\title{
Global Multidisciplinary Learning in Construction Education: Lessons from Virtual Collaboration of Building Design Teams
}

\author{
Soetanto, R. ${ }^{1}$, Childs, M. ${ }^{2}$, Poh, P. ${ }^{3}$, Austin, S. ${ }^{2}$ and Hao, J. ${ }^{3}$
}

\begin{abstract}
Construction is a multidisciplinary activity in which effective communication between parties is essential for successful construction projects. However, the construction industry has been characterised by fragmentation, which prevents seamless communication. This problem has been further exacerbated by the need to communicate over distance within a time constraint in an increasingly interconnected and globalised construction sector. This has brought a particular challenge to the education sector in preparing the future graduates to work in this context. The paper reports on an on-going Hewlett Packard-sponsored project to implement an innovative learning approach which consists of distanced collaboration between students from different disciplines from two Universities in the UK and Canada. The empirical work involved interviews and questionnaire survey at different stages of the project. The preliminary findings reveal the impact of disciplinary training on the development of effective virtual collaboration, although this has been moderated, to some extent, by their earlier (not so positive) experience during the course of the project. The research provides a material for further reflection and may serve as a useful consideration for future development of a guiding framework for effective training of built environment professionals.
\end{abstract}

Keywords: Communication, design team, project-based learning, virtual team.

\section{Introduction}

Design and construction of physical assets is a multidisciplinary activity, which requires contributions from parties who may have different interests and pre-conceived ideas of the project. Although diverse disciplines involved in construction can introduce many innovative ideas for the benefit of the project [1], it is recognised that many causes of poor performance emanate from communication problems between parties during the course of a project [2]. Often, the problems remain hidden, until the construction plan and design are implemented on site. One of the notable influences on successful communication is the educational background and training of individuals in their earlier years of engagement with the built environment sectors.

Advance developments in information and communication technologies (ICTs) have made possible realtime, distanced communication between parties in different locations [3]. However, the 'interface' problems which may have existed between these parties could be further exacerbated by the need to communicate over distance within a time constraint in an increasingly interconnected and globalised construction sector.

\footnotetext{
${ }^{1}$ School of Civil and Building Engineering, Loughborough University, Leicestershire, LE11 3TU, UNITED KINGDOM.

Email: R.Soetanto@lboro.ac.uk

${ }^{2}$ Department of Civil Engineering, Architecture and Building, Coventry University, CV1 5FB, UNITED KINGDOM

${ }^{3}$ Department of Architectural Science, Ryerson University, Toronto, Ontario M5B 2K3, CANADA.
}

Many effective practices that are applicable to traditional collocated teams may no longer be relevant in a distanced environment and require a thorough reexamination.

Developing a better communication practice in the industry would therefore requires fundamental rethinking of the education content and process for the creation of the built environment professionals of the future. The real integration of these educational practices in the workplace would be a difficult task, but educational institutions can contribute by introducing and incorporating aspects of multidisciplinary working to the curricula in the early years of engineers' professional development. Multidisciplinary working presents a significant concepttual challenge for the students as this would require a comprehensive understanding of the interests and orientation of the other subject disciplines, and fit them in the 'jigsaw' of knowledge that is required to produce constructed facilities. This understanding may get better as individuals obtain more experience from their exposure to workplace practice. Further, there are attitudinal requirements that will facilitate successful multi-disciplinary working, for example, a willingness to accept other ideas, levels of trust, a preference to working in teams, the ease to establish relationships with others in the team, which are very much related to the culture at functional, organisational and national levels. These all should be better acquired through experiential learning, rather than infused through the process of knowledge transmission during traditional lecture sessions. 
A project, sponsored by Hewlett Packard (HP), has been initiated to address this challenge by creating an authentic, multi-disciplinary, distanced collaborative working environment that mimics a real industry practice. The project involved groups of students in two built environment departments; one in the UK and the other in Canada. They formed groups comprising civil/structural engineering students in the UK, and architecture students in Canada. The groups worked on a design project, based on a real case study, for a whole academic year (September 2011 to May 2012). This paper reports the initial findings of this investigation, which were obtained from a database of qualitative and quantitative data, including 23 interviews and 134 completed questionnaires from a two stage-survey of participating students. The following sections describe the concept of student-centred learning in the built environment education, definition of virtual teamworking (VT) and the factors influencing effective VT. The discussion focuses on the development of trust and team diversity, a method to identify individual preferred communication modes, group work process, research methods, before the presentation and discussion of findings from both qualitative and quantitative data. Conclusions are drawn to illustrate what the findings may mean for the construction education and professional practices, and to describe limitations and future research.

\section{Student-centred Learning: the Importance of 'Soft' Skills}

The changing operational environment and increasing competition in the higher education sector has promoted the introduction of new pedagogical approaches to teaching and learning. One philosophy underlying an approach to innovative learning is Problem-based Learning (PBL). PBL centres around student activities; the students learn more effectively from the activities they undertake and experience first-hand, rather than from listening to traditional lectures in classroom. In the latter, the students are considered passive recipients of information and knowledge, and the education process is seen as simply an act of transmitting information. The use of term 'problem' may be misleading, as 'problem' may imply (a single) 'solution', which is not the real point of this pedagogy approach [4]. Macdonald and SavinBaden [4] further suggest that 'problems' sit in the centre of the curriculum and are designed to provide focus and motivation for learners. In PBL, a range of solutions or responses are appropriate. As most PBL applications involve some forms of group activities, the learners gain not only technical knowledge, but learn key employability skills such as communication, collaboration and teamworking skills. A UK government-commissioned review of the skills needed for creating sustainable communities highlighted the importance of communication and professional skills for built environment graduates (civil and building engineering), which presently require further development [5]. PBL is aimed at harnessing both hard technical and 'soft' professional skills for future employment, while at the same time, enhancing student experience and motivation through engaging activities in the learning process. PBL promotes 'deep' (in contrast to 'surface') learning, which enables the learners to acquire many transferable skills for employment. It is believed that these 'soft' skills facilitate seamless communication between parties in a multidisciplinary, distributed working environment.

\section{Trust and Performance in Virtual Team- work}

Construction projects are becoming more complex, driven by the increasing requirements from the stakeholders involved, new technology, legal and regulations, to name a few. Proliferation of advanced ICT in the globalised world has permitted projects to engage the best expertise from different parts of the world, and hence encourage the use of VT in construction sector [6]. In this research, VT comprises geographically distributed members who may have diverse expertise and responsibilities, but have to work together as a team to achieve a common project objective. Geographical separation of team members prevents frequent face-to-face communication and physical interactions for decision making, which has brought challenges to managing teamwork in VT. That is, it would be inappropriate to assume that factors influencing collocated team effectiveness are valid for VTs [7 c.f. 8]. Extensive research has been conducted to understand how and why a team achieves its desired outcomes, however relatively little is known about the elements that determine and influence VT performance [9, 10]. Gaudes et al. [3] compiled a comprehensive list of factors that contribute towards the effectiveness of VTs, but there is no pointer to which factors are the most appropriate for a certain context, and the same list could also be applicable for traditional collocated teams. Given the limitation of resources, it would be impractical (or very difficult, if not impossible) to consider all factors, but the research identified trustrelated factors inherent within individual members, that may influence the effectiveness of a VT. The trust was thought to provide a platform to effective VT in the early stages of team development, explained as follows.

Team development describes a progression of a team from merely a collective group to a performing team that capitalises the effort of each member into 
synchronised actions for a common objective. A team is built on trust. Traditionally, trust is nurtured through personal interactions between members over time. Teams develop higher levels of trust when they involved in more social interaction [11 c.f. 3]. When team members are separated, they are less likely to establish one-to-one relationships [12]. Shortage of time due to commercial pressure further prevents the development of trust in teams. Several other factors that may contribute to the lack of (the development of) trust in projects are the different disciplines involved, different working practices (i.e. building standards, regulations, legal framework), and different culture at functional, institutional and national levels [13]. The transient nature of construction projects, coupled with VT working arrangement does really facilitate future association which promotes trust and cooperation. Collocation allows teams to foster shared values, expectation, cohesion and increase commitment to objectives [14]. The absence of frequent face-to-face interaction, aligned expectations and team cohesion may increase the propensity of conflicts between VT members [15].

In virtual collaboration, the word 'trust' is interpreted as perceptions of trustworthiness [16 c.f. 13]. Zolin et al. [13] and Mayer et al. [17] recommended three dimensions underlying perceived trustworthiness: benevolence, ability, and integrity. As defined in Zolin et al. [13], benevolence is the positive perception of the person being trusted by the person doing the trusting [17]. Benevolence can be the outcome of parties having successfully aligned interests and goals in the project $[16,18]$. Ability is the perception that the person to be trusted has the skills and resources needed to perform the task for the project. Zolin et al. [13] distinguished between the skills and effort in that high level of effort (i.e. diligence) does not guarantee success if the party does not have the required skills to undertake the task. In this case, levels of trust may suffer. Integrity refers to the trustee's honesty and moral character as perceived by the person displaying trust. A person to be trusted who displays integrity is seen to be more likely to behave in honourable ways and not deceive their co-workers about their intention to meet commitments and expectations [13].

\section{Diversity in virtual team}

Past research on the relationships between team diversity/composition and team performance has been inconclusive [15]. Some scholars argue that diverse members will bring benefits to the team in terms of new perspectives to problem solving and innovative ideas [19 c.f. 3], others found heterogeneous teams can experience significant difficulties resulting from tension and conflict $[1,15]$. In an evaluation of VT performance, Lee-Kelley and Sankey [9] found that time zone and cultural differences affected communication and team relations more than collocated team. In this research, team diversity has been manifested in bio-demographic/social and functional diversity [15]. Bio-demographic/social diversity includes individual characteristics such as age, gender, race/ethnicity [1]. For the purposes of this research, only 'gender' was included. 'Age' is fairly uniform due to the students being at the same year. Many of the participating students are from overseas, and one would expect diversity of race and ethnicity in the group. However, for ethical reasons, 'race/ethnicity' was not included in the research. Functional diversity arises from differences in educational background, working experience, and functional expertise among team members [15]. The variables included in this research were working experience in the industry, experience in distanced collaboration, and educational background (civil/ structural engineering and architecture). In addition to these variables, students were also assessed by their responses to the VARK questionnaire, described below.

\section{Preferred Communication Modes: the VARK Questionnaire}

Individuals have preferences on the way they work. Due to external factors such as economic pressure, organisational procedures and (domineering) colleagues, the preferences may not align well with the work they actually do. The mismatches can act as an indicator of possible role stress [20]. In the context of the project, work type preference or skills or psychological mismatches in any areas of schedules, priorities, manpower sourcing, technology, administrative procedures, personality and cost, can cause a project to disintegrate [21]. The same information can be presented in different ways; the choice is made by individuals based on their cognitive process of sense making. The mismatches between preferred and actual communication modes may lead to less effective exchanges of information, misunderstanding, disputes and stresses. In educational context, VARK (Visual, Aural, Read/write, Kinesthetic) questionnaire was developed by Neil D. Fleming in 1987 as a means to an identify individual's preferred communication modes [22]. Fleming and Mills [23] found that many students attributed their learning difficulties to the form in which course material was presented. That is, some students found they had difficulties learning in situations where the course material was only presented orally, while others reported similar difficulties when the material was primarily in written form. In comparison to other learning style questionnaires (e.g. Kolb's experiential learning style), VARK has a particular focus on 
identifying on the preference of individuals to take in and give out information. The VARK questionnaire helps users to understand their preferred communication modes, and allows them to reflect, and then facilitate their subsequent learning. Since it was created, the VARK questionnaire has been widely adopted not only in education contexts, but also in businesses. Through online surveys since 2001, a large amount of databases have been collected (with around 2 million responses in 2011 alone) and analysed according to demographic and occupational backgrounds of the respondents. Selfevaluation of the results of the questionnaire produced a reasonable degree of accuracy, as was explained in Fleming [24].

\section{Group Work Process}

During the course of the project, students worked in groups based on a project brief. A project scenario was developed based on a real academic building, which would be built in the future to replace the existing building. The comprehensive project brief included (i) description of purposes of building, requirements of facilities (e.g. rooms, area, environmental aspects), site location and constraints (relationships with the existing building and facilities in the surrounding area), requirements on group formation and work process (meetings, roles of individual student), assessment of tasks with detailed requirements for each project phases, and peer assessment using Web-PA system (see Wilkinson and Lamb [25] for description on Web-PA). In addition to these, design guidance of building standards, structural design codes, poster and presentations were also provided.

Local groups of four students were formed in the participating universities. The UK students studied civil/structural engineering, whereas the Canadian students studied architecture. The teams reviewed the tasks in the project brief and identified previous technical skills to meet the tasks. As the students would be working as a company/team, they were asked to identify people management skills (e.g. leadership, teamworking, communication) that they could demonstrate. Each group was asked to produce one A2-sized poster which should contain technical and management skills of the team, with a view of attracting offers from counterpart teams. The aim was to form the strongest team. Evidence from previous experience was also included in the poster. The teams reviewed the different team posters with a view to negotiating and agreeing with a counterpart team for the formation of a company. The whole exercise was aimed at developing comprehensive understanding of the project brief, and reviewing potential strengths and weaknesses of the team members. This exercise developed their skills for identifying expertise to complement the existing team members.

The teams conducted weekly meetings, and appointed a company leader and secretary to be rotated every four or five weeks, thus enabling each member of the team to carry out each role. The company leaders chaired the weekly project meeting, monitored and co-ordinated the work of the group, ensured that submission dates were met and generally oversaw the day-to-day running of the project team. The company secretary took the meeting minutes, noting any important points discussed, and deputised for the group leader in the event of their absence. The marking scheme combined individual and group marks for each task. The individual marks were derived from the assessment of the task that the individual was responsible for. The group mark was peer- assessed using Web-PA system. The system provides a control mechanism to discourage students being 'passengers' in the team. Further pedagogical benefits from peer assessment to the skills formation in a group work is explained in Wilkinson and Lamb [25].

\section{Research Methods}

A programme of data collection was developed to capture and monitor a number of important aspects of VT collaboration (e.g. conflicts, trust, performance) throughout the project duration (one academic year). This included a series of interviews, questionnaire surveys, personal reflection, grades and tutor assessment feedback at different points with both students participating in the VT activity and students on the same module who had opted to work colocated with students from the same institution ('non-participating' students). This paper reports on the findings obtained from 23 interviews and 134 completed questionnaires obtained from a two-stage survey. The interviews were intended to capture issues and problems faced by the students with their project and to provide understanding of the context within which the project took place. The unstructured interviews were conducted with the groups at different times during the course of the project. The students were asked general and specific questions regarding their project. General questions were asked concerning how the students were getting on with the project, and any issues that may have prevented teamwork. Specific questions covered aspects such as communication technology that they were using, the manner by which they communicated over the distance, issues of trust in the team, and barriers to communication.

The questionnaire sought (i) background information (including course, gender, working experience, expe- 
rience of distance collaboration), (ii) aspects of distance collaboration/team working (such as trust, quality of work, risk, perception on other team members, communication, face-to-face meeting, satisfaction), (iii) VARK (Visual, Aural, Read/write, Kinesthetic) questionnaire, which comprises 16 questions (explaining 16 different situations), each with four different answers, that reflect different ways of taking and giving information for the same situation. For questions related to distance collaboration, the respondents were asked to express their level of agreement against a Likert scale from 1 to 4 where 1 indicates 'strongly disagree'; 2 'disagree'; 3 'agree'; and 4 'strongly agree'. The responses to the VARK questionnaire were coded according to corresponding preferred modes ( $\mathrm{V}, \mathrm{A}, \mathrm{R}$ or $\mathrm{K}$ ). The respondents were allowed to choose multiple answers to each question. The responses corresponding to V, A, $\mathrm{R}$, and $\mathrm{K}$ were then summarised. This highest score indicates the preferred mode. Where there is a tie between two or more modal preferences, the result is considered a double or triple tied preference [24].

The questionnaires were distributed twice to all participating students, at the beginning and halfway through the project. They were given around 15 minutes to complete this short questionnaire (three pages in total), and their responses were collected by the tutors during the session. This process yielded 69 responses (including 32 from the UK and 37 from Canada) in the first survey and 65 responses (including 32 from the UK and 33 from Canada) in the second survey. Only a very few did not hand-in their responses. The responses were analysed using descriptive statistics, chi-square tests obtained from SPSS software. The results of qualitative and quantitative analyses are presented in the following sections.

\section{Developing a Model of Virtual Collaborative Learning: Results from Interviews}

The interviews were transcribed and separate quotes from the students coded according to three types of responses. The first set of these responses were those that made reference to barriers, differences or distances between the groups working locally and those overseas. This is based on the notion of transactional distance [26], which is that the psychological separation between two people in any dialogue (in the examples given by Moore [27] between tutor and student) can be described as a series of constraints of which the technology and geographical distance are only additional elements that arise when that communication is mediated via technology. The position of transactional distance theory is that many of these constraints exist in face- to-face communication, such as the personalities and philosophies of the participants, their skill at communication and the content of the dialogue; the technological constraints noticed in distanced communication are merely those that tend to be focused upon by observers, and are not necessarily the dominant ones.

The model in Figure 1 also summarises the combination of issues related to inputs of learning, process of learning, and outputs or impacts within virtual collaboration environment. The principle of transactional distance has been adapted to inform the model represented here: an input, process, output (IPO) model. In this model, the notion of transactional distance constitutes the 'input' to the act of collaboration, indicating a range of barriers or distances that need to be overcome to form an effective collaboration. Process within an IPO model is the adaptation and activities that acts on the input. Here the students adopt a set of behaviours and activities that bridge this separation. The model groups these processes under the heading of 'alignment strategies'; either the students' observations of how the two groups are aligned, or the process by which they brought the two groups into greater alignment. Peer assessment (using Web-PA system) and tutor intervention provide a 'behavioural control' or moderator to student performance, and are essential elements of the project. The final state is the output; here the outputs which the students and educators valued were the impact the activity had on a range of 'short' and 'long term' aspects, such as employability and personal development, and their performance at the activity. 'Short term' aspects were assessed immediately during and after the process when the students submit their work or make a presentation, and from the personal viewpoint of the students.

The model is not a simple linear relationship however. Applying alignment strategies not only act to reduce existing barriers, alignment strategies also change the perception of the importance of those barriers. For example, effective collaboration techniques will not improve the bandwidth of an internet connection, but in a successful partnership intermittent connectivity is seen as an incidental irritation, whereas an unsuccessful partnership may perceive this as critically limiting their interaction. Similarly motivation is based upon the students' anticipation of a valued output. At present, the model is considered as a thinking tool to guide the research development pathway. It also demonstrates the interplay between different influences of virtual, multidisciplinary, collaborative learning effectiveness for possibly intervention strategies 


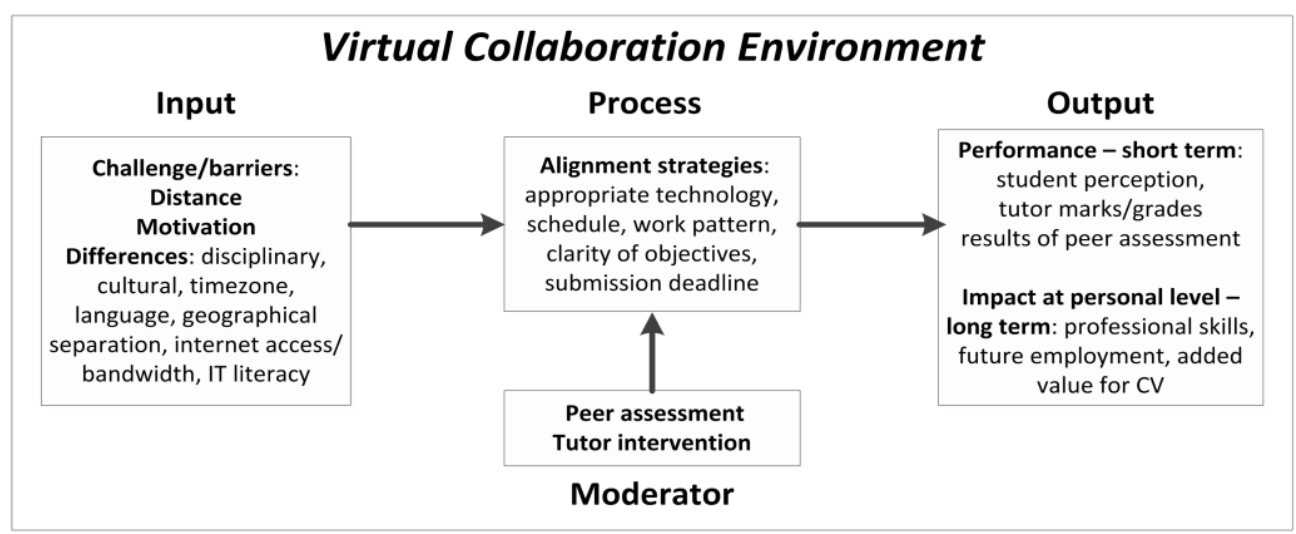

Figure 1. Model of Virtual Collaborative Learning

\section{Results and Discussions from Questionnaire Survey}

From a total of 69 responses in the first stage and 65 in the second stage, male students represent about two-thirds (66\% and $64.5 \%$ respectively), and female, one-third (34\% and $35.5 \%$ respectively). Two-thirds (66\% and $67.2 \%)$ had no work experience in the construction industry. Very few (2 students) had experience in distance collaborative before this project. Apart from experience in distance collaboration categories, the distribution of responses allow comparison between categories (i.e. comparison of responses between UK and Canada, male and female, work experience) to explore the relationship between the categories and the other variables (i.e. VARK responses and 11 factors influencing distance collaboration). Significant relationships in the first and/or second stage questionnaire survey are presented in Table 1.

Table 1. Significant Relationships between Categories and other Variables

\begin{tabular}{lcc}
\hline \multicolumn{1}{c}{ Category versus Variable } & \multicolumn{2}{c}{ Probability value } \\
\cline { 2 - 3 } & Stage 1 & Stage 2 \\
\hline Institution vs. the need to check progress & 0.094 & 0.568 \\
Institution vs. the need to check quality & 0.098 & 0.453 \\
Institution vs. honesty of other members & 0.058 & 0.067 \\
Institution vs. group work exposure to risk & 0.567 & 0.042 \\
Institution vs. face-to-face meeting essential & 0.108 & 0.013 \\
Gender vs. team member competence & 0.020 & 0.148 \\
Gender vs. team member honesty & 0.027 & 0.241 \\
Gender vs. complete work commitment on time & 0.069 & 0.848 \\
Gender vs. satisfaction with teamworking & 0.034 & 0.370 \\
Gender vs. group work exposure to risk & 0.662 & 0.027 \\
Institution vs. VARK & 0.286 & 0.066 \\
Gender vs. VARK & 0.294 & 0.132 \\
\hline
\end{tabular}

The analysis of data obtained from the first stage survey revealed some evidence of a relationship between institutions and three perceptions of distance collaboration, namely (i) checking progress and (ii) quality of work, and (iii) honesty of other members. However, the relationships would not appear too strong (p-value of 0.094, 0.098 and 0.058, respectively). This indicates that higher levels of trust (in terms of 'integrity') could be sustained by providing evidence of consistent performance over the course of the project. The findings of the first and second stage surveys for these three variables were not consistent, as only 'honesty of other members' and institution appear to suggest some relationship. An observation of the first stage data suggests that a higher degree of trust between team members is more likely to be found between students at the Canadian university (i.e. more students chose 'strongly agree', $\mathrm{p}=0.058$ ). However, this appears to be reversed in the second stage finding as more UK students chose 'strongly agree' response and some Canadian students chose 'strongly disagree'. An explanation for this may be found in the fact that architecture students are required to spend more of their time working with their colleagues in the studio, which allows higher level of face-to-face interactions, which in turn, facilitates the development of trust. However, this trust seems to have deteriorated due to failure of UK students to deliver what was required by Canadian students to meet their first submission deadline. The second stage survey has picked this influence up as the survey was administered after the submission deadline. This problem has also reflected in the group interview session. This is well aligned with the fact that Canadian students stressed more importance to face-to-face meetings $(p=0.013)$, which would permit better response to task responsibility. However, this does not seem to lead to self-preservation by the Canadian students, who do not feel that group work will expose them to higher risks $(\mathrm{p}=0.042)$.

The results from the first stage survey revealed significant relationship between gender and four perceptions of distance collaboration: (i) competence of team members $(p=0.020)$, (ii) honesty of other 
members ( $\mathrm{p}=0.027$ ), (iii) other member completing work commitment on time $(\mathrm{p}=0.069)$, and (iv) individual satisfaction with working in team $(p=0.034)$. This suggests that higher degree of trust (in terms of 'integrity') between team members is more likely to be found between female students, who were mostly from the Canadian university. They are also more likely to derive higher levels of satisfaction from working in teams. However, the results of the second stage survey were again inconsistent with those of the first stage survey (none of the four were significant). One possible explanation is deterioration of trust as explained in the previous paragraph. However, this does not seem to lead to an attitude of self-preservation by female students, who do not feel that group work will expose them to higher risks $(p=0.027)$.

The results of the VARK questionnaire in relation to institutions and gender categories, obtained from the first stage survey are presented in two histograms in Figure 2. From the histogram on the left, it can be seen that UK students tend to prefer aural and $\mathrm{read} / \mathrm{write}$ modes, whereas Canadian students tend to prefer visual and kinesthetic modes. The same tendency was also found in the gender categories, as detailed in the histogram on the right. However, the relationships were not significant (with $\mathrm{p}$-value of 0.286 and 0.294 respectively). This tendency is confirmed by the second stage survey (with stronger p-value of 0.066 and 0.132 ). The VARK website, which has been online since 2001, can provide a comparison of this finding with the general student population. Based on online responses from around 80,000 students from different levels (including universities, colleges and high schools), Fleming [24] found significant differences (based on chi-square analysis) between males and females in their preferred communication modes with men have more kinesthetic responses and women more $\mathrm{read} / \mathrm{write}$ responses. If the responses in this research should demonstrate the same tendency, the finding of our research suggests that training in the subject disciplines can influence the preferred communication mode of the students. In this case, there is tendency of different communication modes between the two professions, with architects preferring visual and kinesthetic modes, and civil/ structural engineers preferring aural and read/write modes.

\section{Conclusions}

This research has considered factors that may influence the effectiveness of virtual team working through an investigation of authentic simulated learning environment where students work on a real case study project. A model of virtual collaborative learning has been developed based on the results of interviews. As a thinking tool, the model depicts the relationship between influencing factors in virtual teamworking, informs the interpretation of questionnaire data, and provides a platform to develop the research.

The findings suggest that the different disciplines in this project tend to prefer different communication modes with UK students (civil/structural engineers, male majority) preferring aural and read/write modes, whereas Canadian students (architects, female majority) preferring visual and kinesthetic modes. A comparison of this finding with the general student population, as demonstrated by Fleming [24], reveals the potential impact of disciplinary training to the students' preferred communication modes. Further evidence indicates that higher levels of 'integrity' trust could be sustained by providing evidence of consistent performance over the course of the project, and higher degrees of 'integrity' trust between team members is more likely to be found between female students, who were mostly from the Canadian university (architects).
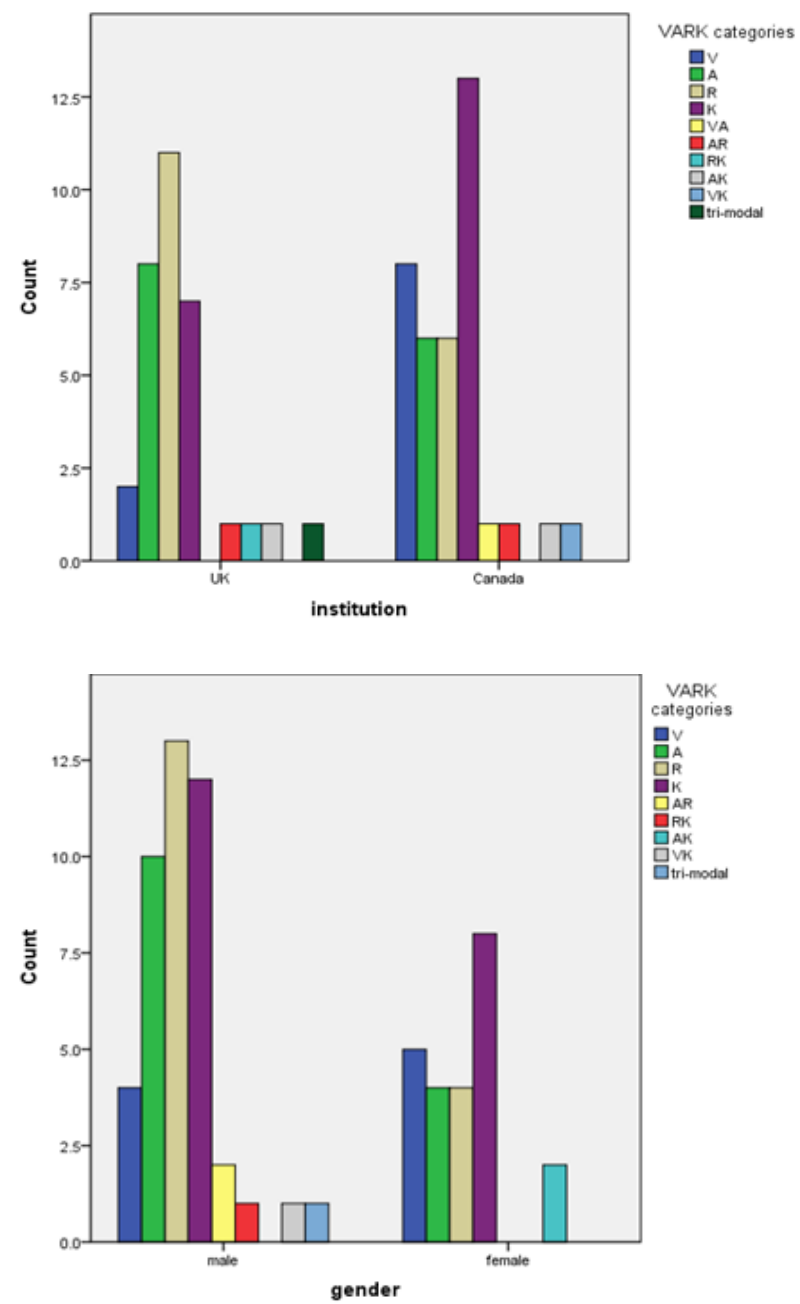

Figure 2. VARK Profile for Institution and Gender Categories (from first stage survey) 
They are also more likely to derive higher levels of satisfaction from working in teams. However, the second stage survey revealed that trust seems to have been deteriorated due to the failure to meet the expectation of the other group members. If the 'integrity' trust is regarded as an essential foundation for an effective VT working, the disciplinary training may have an influence on the development of effective virtual collaboration. It could be argued that architectural students are required to spend more of their time working with their colleagues in the studio, which allows higher levels of face-to-face interactions. This 'collegiate' training may facilitate the development of 'integrity' trust. However, in the virtual collaborative environment, this 'integrity' trust would need to be nurtured by consistent demonstrated performance (e.g. meeting deadline and expectations of other members). This reciprocal relationship is further emphasised by individual satisfaction (as one measure of performance of teamwork) which was found to be derived from the performance of the other members.

The findings have implications for education and industry practices that can cut across national boundaries. The findings can be considered as a pointer to the possibility that construction educators may have not sufficiently addressed the grand idea of 'integration' between the disciplines/professions in the built environment, despite all the rhetoric and efforts that have been expended. Radical changes would not happen overnight, but multi-disciplinary collaborative working over distance should be made a fundamental element of the curricula. Currently, this skill is still considered high added value for employability, however in the future, this will be an essential part of built environment education. The research presented here has several limitations. Firstly, a small sample has prevented stronger results of statistical tests. Secondly, other performance measures (such as assessments from tutors and industry practitioners, team cohesion) would need to be examined and incorporated in the research to investigate their relationships with the factors. Thirdly, inferences to the general (practitioners) population should be drawn with caution, as practitioners may experience other influences in the workplace. They suggest future research areas.

\section{Acknowledgement}

The authors wish to thank Hewlett Packard (HP) through the Office of Global Social Innovation for funding this research, International Society for Technology in Education (ISTE) and Global Collaboratory Consortium for facilitating the project. Special thanks go to Dr Constantine Katsanis (Ecole de Technologie Superieure (ETS), Montreal, Canada) for his involvement and contribution to the project. Thanks are due to all staff involved.

\section{References}

1. Horwitz, S.K. and Horwitz, I.B., The Effects of Team Diversity on Team Outcomes: A Metaanalytic Review of Team Demography, Journal of Management, 33(6), 2007, pp. 987-1015.

2. Dainty, A, Moore, D. and Murray, M., Communication in Construction: Theory and Practice, Taylor and Francis, London, 2006.

3. Gaudes, A., Hamilton-Bogart, B., Marsh, S. and Robinson, H., A Framework for Constructing Effective Virtual Teams, Journal of E-working, 1, 2007, pp. 83-97.

4. Macdonald, R. and Savin-Baden, M., A Briefing on Assessment in Problem-based Learning, Learning and Teaching Support Network (LTSN) Generic Centre - Assessment Series No. 13, York, 2004.

5. Egan, J., Skills for Sustainable Communities, Office of the Deputy Prime Minister, London, 2004.

6. Rezgui, Y., Exploring Virtual Team-working Effectiveness in the Construction Sector, Interacting with Computers, 19, 2007, pp. 96-112.

7. Potter, R.E. and Balthazard, P.A., Understanding Human Interaction and Performance in the Virtual Team, Journal of Information Technology Theory and Application, 4(1), 2002, pp. 1-23.

8. Kirkman, B.L., Rosen, B., Tesluk, P.E. and Gibson, C.B, The Impact of Team Empowerment on Virtual Team Performance: The Moderating Role of Face-to-face Interaction, Academy of Management Journal, 47(2), 2004, pp. 175-192.

9. Lee-Kelley, L. and Sankey, T., Global Virtual Teams for Value Creation and Project Success: A Case Study, International Journal of Project Management, 26, 2008, pp. 51-62.

10. Algesheimer, R., Dholakia, U.M. and Gurau, C., Virtual Team Performance in a Highly Competetive Environment, Group \& Organization Management, 36(2), 2011, pp. 161-190.

11. Jarvenpaa, S. and Leidner, D., Communication and Trust in Global Virtual Teams, Organization Science, 10(6), 1999, pp. 791-815.

12. Chinowsky, P.S. and Rojas, E.M., Virtual Teams: Guide to Successful Implementation, Journal of Management in Engineering, 19(3), 2003, pp. 98-106.

13. Zolin, R., Hinds, P.J., Fruchter, R. and Levitt, R.E., Interpersonal Trust in Cross-functional, Geographically Distributed Work: A Longitudinal Study, Information and Organization, 14, 2004, pp. 1-26. 
14. Daim, T.U., Ha, A., Reutiman, S., Hughes, B., Pathak, U., Bynum, W. and Bhatla, A., Exploring the Communication Breakdown in Global Virtual Teams, International Journal of Project Management, 30, 2012, pp. 199-212.

15. Kankanhalli, A., Tan, B.C.Y. and Wei, K.K., Conflict and Performance in Global Virtual Teams, Journal of Management Information Systems, 23(3), 2007, pp. 237-274.

16. Hardin, R., Trust and Trustworthiness, Russell Sage Foundation, New York, 2000.

17. Mayer, R.C., Davis, J.H. and Schoorman, D., An Integrative Model of Organizational Trust, Academy of Management Review, 20(3), 1995, pp. 709-734.

18. Das, T.K. and Teng, B., Between Trust and Control: Developing Confidence in Partner Cooperation in Alliances, Academy of Management Review, 23(3), 1998, pp. 491-512.

19. Staples, S., Wong, I.K. and Cameron, A.F., Best Practices for Effective Virtual Teams, Idea Group Publishing, Kingston, ON, 2005.

20. Lee-Kelley, L., Locus of Control and Attitudes to Working in Virtual Teams, International Journal of Project Management, 24, 2006, pp. 234-243.

21. Thamhain, H.J. and Wilemon, D.L., Conflict Management in Project Life Cycles, Sloan Management Review, Spring, 1975, pp. 31-50.
22. Marcy. V., Adult Learning Styles: How the VARKC Learning Style Inventory can be Used to Improve Student Learning, Perspective on Physician Assistant Education, Journal of the Association of Physician Assistant Programs, 12(2) Spring, 2001.

23. Fleming, N.D. and Mills, C., Not another Inventtory, Rather a Catalyst for Reflection, To Improve the Academy, 11, 1992, p. 137.

24. Fleming, N.D., VARK: A Guide to Learning Styles. [http://www.vark-learn.com/english/page.asp?p= faq] accessed 15 March 2012.

25. Wilkinson, N. and Lamb, F., WebPa Online Peer Assessment: Resource Pack. Loughborough: Loughborough University, 2010. Available for download from http:/www.webpa.ac.uk/files/WebPA_resource_ pack-low-res.pdf

26. Childs, M. Analysis and Description of Education Employing Technological Platforms: Terminology, Features and Models, in L. Clouder and A. Bromage (eds) Interprofessional E-Learning and Collaborative Work: Practices and Technologies, IGI Global, 978-1-61520-889-0, 2010, pp. 46-60.

27. Moore, M.G., Theory of Transactional Distance, in Keegan D. (ed.) Theoretical Principles of Distance Education, Routledge, London, 1993, pp. 22-38. 